\title{
Mycobacterium africanum
}

National Cancer Institute

\section{Source}

National Cancer Institute. Mycobacterium africanum. NCI Thesaurus. Code C85544.

A species of Mycobacterium that is a member of the Mycobacterium tuberculosis complex. It is most commonly found in West African countries and causes symptoms of infection resembling those of $\mathrm{M}$. tuberculosis. 